\title{
AESTHETIC PERCEPTION OF THE RUSSIAN SOUND SPEECH BY GERMANS (A CASE STUDY OF GERMAN INTERNET FORUMS)
}

\author{
Elena A. Shesterina \\ Moscow State Institute of International Relations (University), \\ 76, Prospect Vernadskogo, Moscow, 119454, Russia.
}

\begin{abstract}
The article is devoted to the aesthtic assessment of the sound of Russian speech as reflected in German Internet forums. Segmental and suprasegmental features of Russian pronunciation which evoke in native speakers of German empathy and / or antipathy towards Russian sounding speech, are described. The ordinary Germans' naive assessment of Russian souding speech differs from that by professional linguists. Germans who are not familiar with the theoretical basis of the phonetic structure of the Russian language pay attention, first of all, to those pronunciation features that are not characteristic of the phonetic basis of the German language. Among them on segmental level are the following: trembling sonant $[r]$, vowel $[\mathrm{f}]$ and back-lingual slit $[\gamma]$ after vowels [e], [i] and consonants $[l]],\left[n^{j}\right],[j]$, the pronunciation of which in German in this position is pronounced as ich-Laut [ç]. The Germans also seem to dislike clus-

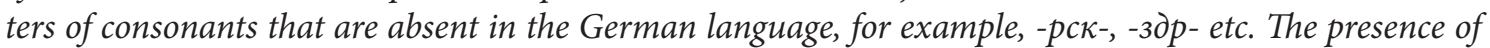
these sounds in the Russian language allows ordinary Germans to characterize Russian sounding speech as rude, despite the remarks of the Germans that there are many "soft" sounds i.e. palatalized consonants in the Russian language. The main difference at the suprasegmental level, which in the scientific literature is designated as the opposition of the German "staccato" and Russian "legato", finds its confirmation in the statements of German members of the forum. The rhythmic organization of Russian speech is assessed by common Germans as discordant and indistinct, since, unlike German speech, Russian speech is characterized by relaxed articulation, non-forced vocalization, an extended melodic range and an irregular rhythmic patterns. In addition, the use of different pitch movements in friendly and aggressive communication encourages Germans to qualify the speech of Russian speakers in obvious situations of friendly communication as confrontational.
\end{abstract}

Keywords: sounding speech, sound aesthetics, speech perception, internet forums, staccato and legato, segmental and suprasegmental levels

For citation: Shesterina, E.A. (2021). Aesthetic Perception of the Russian Sound Speech by Germans (a Case Study of German Internet Forums). Linguistics \& Polyglot Studies, 7(5), pp. 102-110. https://doi. org/10.24833/2410-2423-2021-5-29-102-110 


\title{
ПРЕДСТАВЛЕНИЯ НЕМЦЕВ ОБ ЭСТЕТИКЕ ЗВУЧАНИЯ РУССКОЙ РЕЧИ (НА МАТЕРИАЛЕ НЕМЕЦКИХ ИНТЕРНЕТ-ФОРУМОВ)
}

\author{
Е.А. Шестерина
}

Московский государственный институт международных отношений (университет) МИД России, 119454, Россия, Москва, пр. Вернадского, 76

\begin{abstract}
Аннотация. В статье проводится анализ высказываний на немецких интернет-форумах, в которьх даётся оценка эстетической стороне звучания русской речи. Описываются сегментные и супрасегментные признаки русского произношения, вызываюшие у носителей немеикого языка чувства симпатии и/или антипатии в отночении благозвучности русской речи. Наивные представления простьх носителей немецкого языка отличаются от оценок звучания русской речи профессиональными тингвистами. Немиь, не знакомые с теоретической базой фонетического строя русского языка, обращают внимание, прежде всего, на те произносительные особенности, которые не свойственны фонетической базе немецкого языка. Среди средств реализаиии сегментного уровня, которые отмечают немецкие форумчане, называются дрожащий сонант [p], гласный [bl] и заднеязычный щелевой [x] после гласных [e], [u] и согласных [л'], [н'], [ü], который в немеиком языке в данной позииии произносится как ich-Laut [ç]. Непривлекательными представляются немиам и нетипичные скопления согласных, отсутствующие в немеиякм языке, например, -rsk-, -sdr и др. Наличие в русском языке этих звуков даёт основание простым немиам характеризовать русскую звучашую речь как грубую, несмотря на замечания немцев о наличии в русском языке большого количества «мягких», то есть палатализированньх согласных. Основное различие на супрасегментном уровне, которое в научной литературе обозначается как противопоставление немецкого "стаккато» и русского "легато», находит своё подтверждение и в высказываниях немеиких форумчан. Ритмическая организация русской звучащей речи оиенивается простыми немиами как неблагозвучная и невнятная, так как в отличие от немецкой звучащей речи русская речь характеризуется ненапряжённой артикуляцией, неборсированным голосообразованием, расширенным мелодическим диапазоном и неупорядоченным ритмическим рисунком. Кроме того, использование различного характера движения тона в дружеской и агрессивной коммуникации побуждает немцев квалифицировать речь русскоговорящих в очевидных ситуациях дружеского общения как конфронтационную коммуникацию.
\end{abstract}

Ключевые слова: звучащая речь, эстетика звучания, восприятие речи, интернет-борумь, стаккато и легато, сегментный и супрасегментный уровни

Для цитирования: Шестерина Е.А. (2021). Представления немцев об эстетике звучания русской речи (на материале немецких интернет-форумов). Филологические науки в МГИМО. 7(5), C. 102-110. https://doi.org/10.24833/2410-2423-2021-5-29-102-110

\section{1. Введение}

$\Pi$ роблема восприятия немцами русской речи, а вместе с тем выявление и фоностилистическая интерпретация сегментных и супрасегментных характеристик русской речи, влияющих на характер её эстетического восприятия носителями немецкого языка, не часто 
становились предметом специального изучения. Тем не менее исследования в заявленном русле представляются актуальными, поскольку в настоящее время существует потребность в определении причин появления негативных или позитивных эмоций у представителей одной лингвокультурной общности в зависимости от интерпретации услышанной ими иностранной речи и идентификации говорящего как принадлежащего к тому или иному этносу, что активизирует определённые стереотипы и вызывает либо симпатию, либо антипатию в отношении него.

В ракурсе изучения оценки произношения немецкого и русского языков больше всего представлены работы, занимающиеся эмоциональностью звучащей речи [см. напр.: $1 ; 2$ ]. Аудитивный и акустический анализ при оценивании звучащей речи представляет особый исследовательский интерес для Галльской фонетической школы университета им. Мартина Лютера в Галле (Германия) [см. напр.: 9; 10]. Большое исследование разговоров детей на материале немецкого и русского языков предпринято Н.С. Поспеловой, в котором проводится тщательный аудитивный анализ спонтанной речи. Автор привлекает русских и немецких экспертов-фонетистов и составляет каталог оценки просодических признаков спонтанной речи в обоих языках [5].

Заслуживает внимания экспериментально-фонетический анализ русской и немецкой речи, проведённый Р.К. Потаповой и В.В. Потаповым. Авторы приходят к выводу, что интегративная картина немецкой звучащей речи по полному праву соответствует представлению о ней как о «стаккато» (в терминологии Ф. Трояна [11]: напряжённое артикулирование, форсированное голосообразование (твёрдый приступ и сильный отступ), толчкообразная динамика слогов, узкий мелодический диапазон, тяготение к монотонности звучания и т.п. Русское же произношение соответствует звучанию «легато»: ненапряжённая артикуляция, нефорсированное голосообразование, расширенный мелодический диапазон, неупорядоченный ритмический рисунок и т.п. [6, c. 208-209].

Среди последних работ в социолингвистическом русле, занимающихся восприятием немцами звучания речи иностранцев, стоит назвать проект «Spracheinstellungen», проведённый Институтом немецкого языка (Мангейм) совместно с кафедрой социальной психологии Мангеймского университета. Мы представляем полученные результаты лишь в графическом виде (Диаграмма 1 и Диаграмма 2), которые свидетельствуют о приписывании немцами русской звучащей речи преимущественно заниженных эстетических качеств по сравнению с другими иностранными языками, представленными в повседневной жизни Германии [8, с. 27-30]:

Диаграмма 1. Результаты обработки ответов на вопрос:

«Какой или какие иностранные акиенты Вам нравятся?» (возможно назвать несколько вариантов)

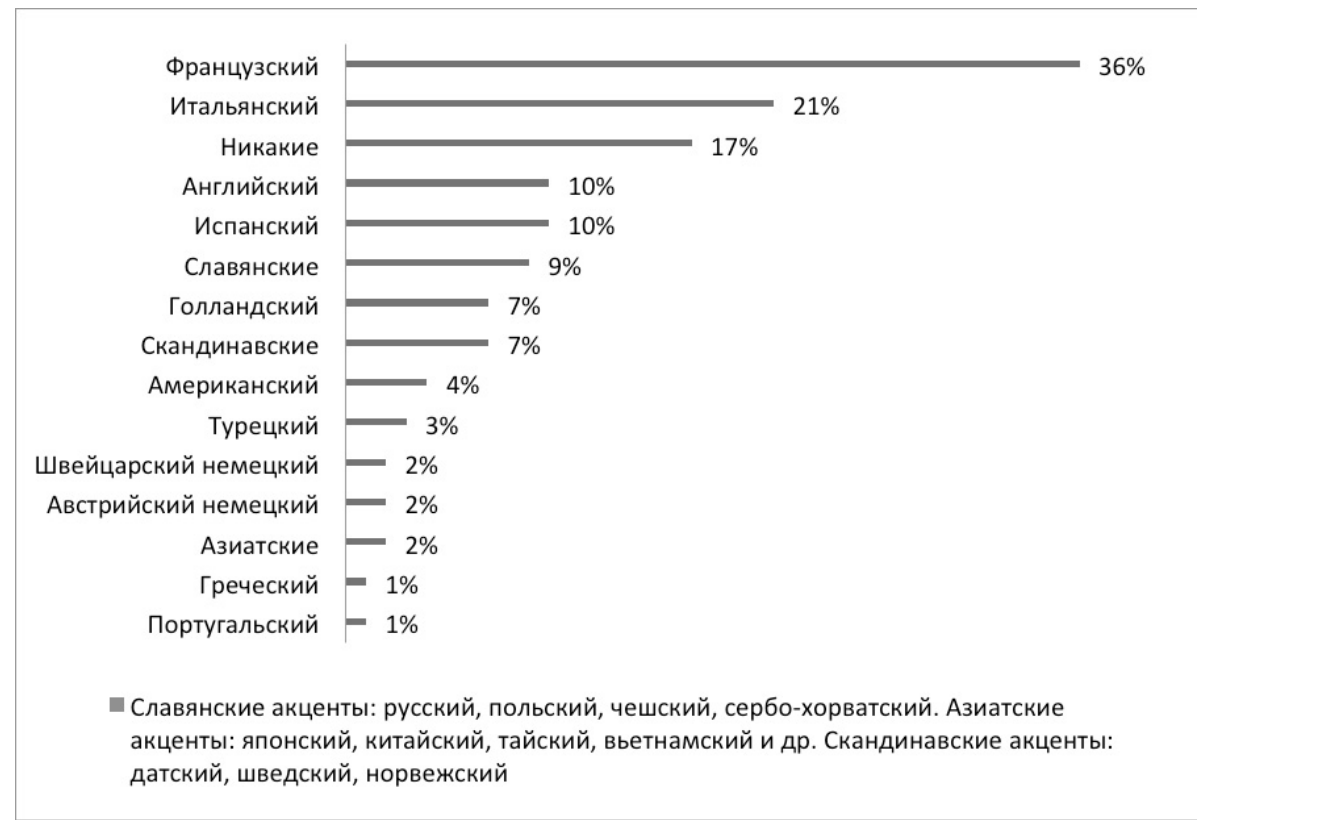


Диаграмма 2. Результаты обработки ответов на вопрос:

«Какой или какие иностранные акценты Вам не нравятся?» (возможно назвать несколько вариантов)

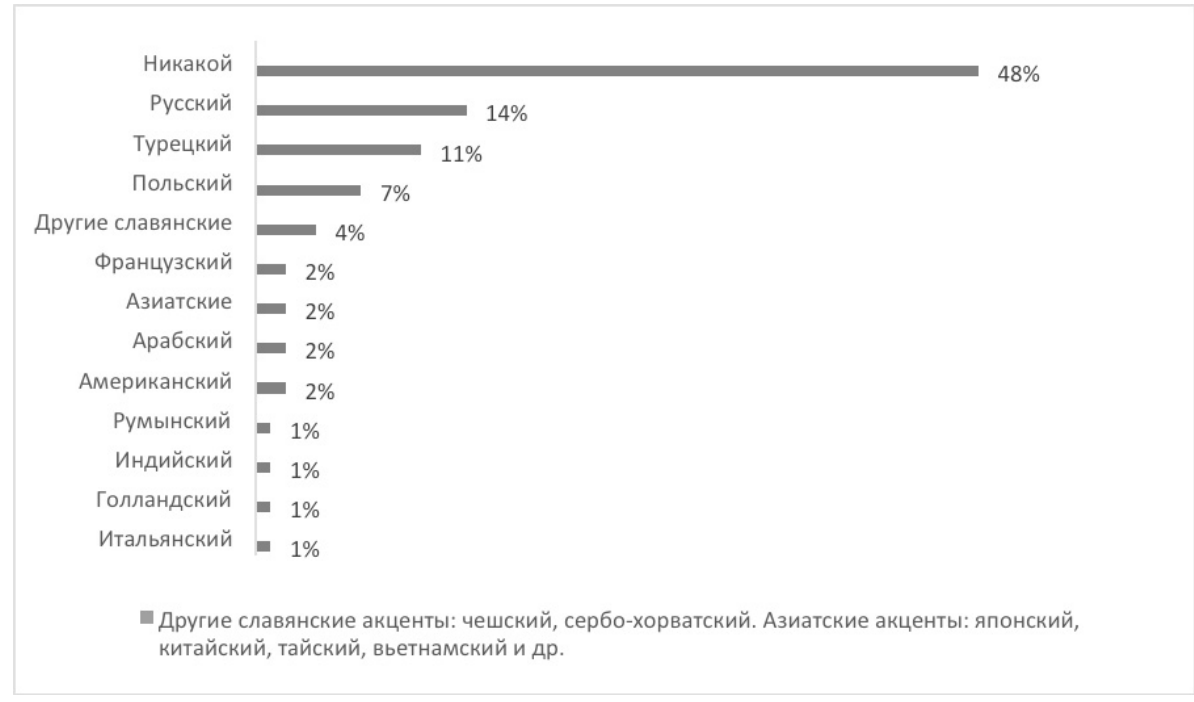

В литературе по исследуемой проблематике отмечается, что исследование данных о параметрах звучащей речи осуществляется в основном инструментальным путём лингвистами-профессионалами, которые опираются на объективные фонетические и фонологические критерии. Такая оценка звучания речи отличается от наивных восприятий её обычными носителями языка [4, с. 39]. Чтобы заполнить эту лакуну, в рамках предпринятого исследования мы ставим цель - выявить сегментные и супрасегментные признаки русского произношения, вызывающие у обычных носителей немецкого языка чувства симпатии и/или антипатии в отношении эстетики звучания русской речи.

\section{2. Методика и материал исследования}

В качестве материала исследования послужили дискуссии на немецкоязычных форумах в 20162019 годах, посвящённые восприятию немцами речи на иностранных языках (www.forumla.de, www. https://www.bym.de/forum/, www.gutefrage.net, www.ioff.de, https://www.forum-3dcenter.org/vbulletin/, de.answers.yahoo.com). В результате сплошной выборки было отобрано 141 высказывание с оценкой звучащей русской речи. На начальном этапе анализа все высказывания были распределены на 2 группы: симпатия и антипатия при восприятии звучания русской речи. Далее в каждой группе были выделены сегментные и супрасегментные признаки русского произношения, которые вызывают у носителей языка эстетические чувства или отсутствие таковых. Третий этап анализа - контекстное изучение зависимости тех или иных сегментных и супрасегментных признаков русского произношения с эстетическим восприятием носителями немецкого языка русского произношения.

\section{3. Результаты и обсуждение}

Проведённый анализ высказываний немецких форумчан относительно звучания русского языка в общем и целом подтверждает результаты проекта «Spracheinstellungen», проведённого Институтом немецкого языка совместно с кафедрой социальной психологии Мангеймского университета. Если фонетику русского языка авторы высказываний считают «симпатичной», то язык часто упоминается наряду с другими языками, которые в рейтинге проекта «Spracheinstellungen» занимают первые 8 строчек, например:

- Rein vom Phonetischen her gefallen mir Russisch, Italienisch und Gälisch am besten ${ }^{1}$.

Высказывания приводятся в орфографии и пунктуации их авторов. 
- Französisch, Russisch und Englisch finde ich am schönsten.

- Spanisch und russisch sind sehr geil.

Если носители немецкого языка воспринимают русское произношение как «несимпатичное», то русский язык преимущественно ставится в один ряд с другими языками, которые в рейтинге проекта «Spracheinstellungen» занимают места с 1 по 8, как показывают следующие примеры:

- Alle skandinavischen Sprachen, Polnisch, Russisch etc: Nix für mich.

- Jo ich kann kein russisch oder polnisch oder so hören, da bekomme ich plaque.

- Osteuropäische und arabische Sprachen mag ich auch nicht.

- Ganz schrecklich finde ich Russisch und Holländisch...

- Hässlich finde ich chinesisch weil sich das so abgehackt anhört und slawische sprachen wie russisch und polnisch.

В некоторых высказываниях отмечается позитивное восприятие русского произношения, но с той оговоркой, что имеется в виду звучание русского языка в песнях, например:

- Mir gefallen Deutsch, Englisch, Spanisch, Französisch, Griechisch, Isländisch und Russisch (gesungen). Ich meine hierbei nur den Klang.

Нередки случаи, когда разные немецкие форумчане называют в качестве характерных особенностей русского произношения как позитивные, так и негативные признаки. При этом в их оценке звучания русской речи может наблюдаться склонность оценивающего лица рассматривать её либо как привлекательную, ли как непривлекательную. Это зависит от того, какой произносительный параметр оказывает большее воздействие на эстетический вкус носителя немецкого языка, например:

- Klingt hart, obwohl viele Konsonanten auch weich gesprochen werden.

- Russisch ist sehr hart, aber auch ganz schön.

В качестве основного фактора, который побуждает немецких форумчан негативно оценивать звучание русской речи, отмечается непривычный для носителей немецкого языка фонетический строй русского языка. Это наглядно показывают следующие примеры:

- Tschechisch finde ich nicht haesslich, aber anfangs verrenkt man sich dabei den Kiefer. Fuer Polnisch, Russisch, Bulgarisch etc. gilt wohl Aehnliches, die Aussprache ist einfach zu ungewohnt für uns.

- Merkwürdige Laute, die es im Deutschen nicht gibt...

Среди факторов, преимущественно влияющих на негативное восприятия русского языка, немецкие форумчане отмечают наличие в языке звуков, которые отсутствуют в немецкой фонетической системе. В первую очередь это касается дрожащего сонорного [р]:

- Ich kenn das nur so, dass die immer das $R$ so komisch sprechen.

- [Mir gefällt Russisch nicht] vielleicht auch wegen dem rollenden „ $R$ “.

Для имитации русского акцента немцы часто заменяют в своей речи немецкий „ $\mathrm{R}^{“}$ во всех позициях на русский дрожащий сонорный [p]:

- Hört sich bisschen russisch an mit vielen Rrrrrrs und so aber alle finden ihn toll.

Непривычными для немцев представляются также русский заднеязычный щелевой [x] и гласный [ы], отсутствующий в немецком вокализме. Заднеязычный щелевой $[\mathrm{x}]$ становится особенно заметным в русском акценте говорящего на немецком языке в позициях после гласных [e], [и] и согласных [л'], [н'], [й], где, в свою очередь, используется немецкий переднеязычный ich-Laut, например:

- Wie mache ich einen russischen Akzent? Ausser dem rollenden $r$, solltest Du das "ch“ anders aussprechen. Z.B.: ich möchte... da sprichst Du „ch“ wie bei dem Wort „Acht“.

Неблагозвучным представляется немцам скопление согласных, нетипичное для немецкого произношения и сложное для произнесения, как, например, сочетания -рск- и -здр- в нижеприведённом высказывании:

- Russisch hört sich noch schlimmer an... Krasnojarsk, Novosibirsk, nasdrovje... würg.

Достаточно широко распространена оценка русского языка как «твёрдого» („hart“), а потому грубого. В форумах обнаружены лишь единичные случаи позитивного восприятия данного признака, например: 
- Russisch ist sehr hart, aber auch ganz schön.

Большинство же высказываний о твёрдости русского произношения имеет негативную коннотацию, например:

- Nichts gegen die russische Sprache, aber da kommt mir die Sprache recht rau vor.

- wer findet den Russisch schön das ist die schlimmste Sprache von allen eine härtere und Agressivere Sprache gibt es nicht...

- Weil Russisch eine „harte“ Aussprache hat.

- Russisch klingt mir zu hart.

У немцев, не владеющих русским языком, создаётся впечатление того, что русские всё время разговаривают друг с другом на повышенных тонах, о чем свидетельствуют многочисленные оценки форумчанами русского звучания как агрессивного, например:

- Russisch, Polnisch und Türkisch ... klingt irgendwie so, als wenn man immer nur Flucht und spuckt.

- Vielleicht weil du kein russisch kannst und die Sprache nicht verstehst, dann hat man finde ich das Gefühl, dass die Menschen über irgendetwas Böses reden und deswegen hört es sich auch gefährlich an oder du hast unbewusst vorurteile gegenüber russen.

- Wenn ich Tiere treibe die nicht gehen wollen dann benutze ich die schöne russische Sprache. So in der Richtung hört sich das für mich an.

Квалификация немцами звучания русской речи как агрессивного объясняется разным характером движения тона в определённых коммуникативных ситуациях. Замечено, что выражение негативных интенций и агрессии в немецкой речи передаётся восходящим движением тона. В русском же языке негативное напряжение говорящих передаётся преимущественно нисходящей мелодией $[1$, c. 20]. На описываемую разницу в интонационном оформлении агрессивных интенций в немецком и русском языках обращает внимание Н.А. Каск в своём исследовании речи российских актёров, пытающихся изобразить гнев и напряжённость в немецком языке. Отмечается, что для этого актёры прибегают к нисходящему движению тона, как бы они это сделали в русской речи [3, с. 256]. Таким образом, у немецких реципиентов восходящее движение тона в эмоциональной дружеской беседе русскоговорящих собеседников подсознательно интерпретируется как агрессивная коммуникация и создаётся некорректный образ русской речи.

Несмотря на то, что фонетика русского языка в отличие от немецкого произношения изобилует случаями палатализации согласных, немцы тем не менее чаще отмечают твёрдость звучания русской речи. В то же время факт смягчения согласных в русском языке квалифицируется некоторыми форумчанами как чрезмерное и вызывает у них неодобрение. Сравним следующие примеры:

- Weich gesprochene Sprachen wie Russisch finde ich dagegen vom Klang her schrecklich.

- Zu Chinesisch habe ich die gleiche Meinung wie zu Russisch - zu weich.

Среди форумчан бытует мнение, что русская речь в исполнении женщин звучит привлекательнее, чем из уст мужчин. Звучанию женской речи иногда даже приписывается оттенок сексуальности, например:

- Wenn eine Russin dagegen anfängt, in ihrer Landessprache zu sprechen, finde ich das rattenscharf! Allein der Akzent, das hat für mich irgendwie etwas raues und verruchtes.

- Russisch hmm bei manchen Damen kommts geil, bei vielen anderen auch asozial.

- Russisch ist nur sexy, wenn die frau eine feine stimme hat, ansonsten wird's schlimm.

Следует отметить, что проанализированный корпус примеров позволил также обнаружить суждения форумчан о сексуальном звучании русского языка независимо от гендерного фактора:

- Ich find russisch auch sexy „puschistik i laska“.

- Ich lieeeebbbeee Polnisch und Russisch... Ich mag sie weil sie so sexy klingen und alles so verniedlichst wird. Sie klingen weich und fließend.

На гендерные различия немецкие форумчане обращают внимание при оценивании высоты тона говорящих на русском языке. В отличие от выше описанных случаев общей сексуальной коннотации говорения русских женщин, высота тона женского голоса подвергается негативной оценке со стороны немцев: 
- Außerdem finde ich die Stimmlage, in der die Sprache vor allem von den Russinnen gesprochen wird, so richtig schlimm. So schrill und hoch, es klingt so nach Huhn.

- Alle diese Sprachen aus dem Osten - Polnisch, Rumänisch, Russisch ... für mich einfach schlimm anzuhören - komischerweise haben die Frauen auch so unheimliche Fistelstimmen.

В немецких интернет-форумах зафиксированы единичные случаи позитивной оценки высокого тона говорящих на русском языке, как в следующем примере:

- Und die Frauen heben und senken den Ton stärker als die deutschen Frauen, darum hören sie sich viel sinnlicher und charmanter an. Sag ich selbst als Frau.

Ещё одна характеристика русской речи, на которую обращают внимание немецкие форумчане, это - нечёткое произнесение звуков, например:

- Es [Russisch] klingt in meinen Ohren, als wenn jemand einen riesigen Klumpen Kaugummi im Mund hat und versucht, zu sprechen.

- [Russisch] klingt wie wenn man eine Bohne gurgelt.

- Franz ist eleganter, hat eine Melodie. Russisch klingt unsauber und wirkt abgehackt.

- [Russisch] hört sich schäbig an.

- Slawische Sprachen: grauenvoll, als würden sich die sprechen unter wasser befinden.

Восприятию немцами звучания русской речи как нечёткого можно найти следующее объяснение. В обоих языках присутствует редукция безударных гласных, ассимиляционные процессы и оглушение звонкого согласного в позиции конца слова. Но как отмечает М.К. Рогова, последнее фонетическое явление в немецком служит сигналом разграничения как слов в высказывании, так и морфем внутри слова [7, с. 20]. Эффект разграничения слов и морфем в немецкой речи усиливается благодаря твёрдому приступу и произнесению глухих взрывных согласных с придыханием. В сумме воздействия перечисленных факторов прослеживаются бо́льшие паузы, а вместе с ними и более чёткое разграничение между немецкими морфемами и словами. Отсутствие дополнительных фонетических механизмов разграничения морфем и слов в русской речи вызывает у немецких реципиентов ощущение того, что носители русского языка говорят быстро и невнятно.

Немецкие форумчане обращают внимание на случаи утрированной долготы произнесения русских гласных в определённых коммуникативных ситуациях, что с их точки зрения придаёт русской речи протяжность, которая некоторым немецким реципиентам нравится, например:

- Alles zieht sich und klingt weich und "genuschelt“...

Большинство же немецких форумчан расценивают протяжность русской речи как неэстетичное свойство, как в ниже представленных высказываниях:

- Wenn ich russisch höre denke ich immer an einer kreissäge! Z.b. bei Niiieeeeett oder bleeeeeeeeiid.

- Harte Aussprache und bei gewissen Wörtern eine Ausdehnung des Wortes, jetzt mal als Beispiel das Wort „nicht" hört sich in etwa an wie "njieacht“.

\section{4. Выводы}

1) Проведённый анализ высказываний немецких форумчан относительно эстетической стороны звучащей русской речи показал, что немцы, не знакомые с теоретической базой фонетического строя, обращают внимание, в первую очередь, на те произносительные особенности русского языка, которые контрастируют с фонетической базой немецкого языка.

2) На сегментном уровне оценке эстетической стороны звучания русской речи подвергаются переднеязычный дрожащий сонант [p], гласный [ы] и заднеязычный щелевой $[\mathrm{x}]$ после гласных [e], [и] и согласных [л'], [н'], [й], поскольку в немецком языке в данной позиции произносится ich-Laut [ç].

3) На супрасегментном уровне эстетическое восприятие русской звучащей речи основывается на противопоставлении восприятия динамики слога: «стаккато» в немецком и «легато» в русском языке. Бо́льшая напряжённость речевого аппарата при производстве немецкой речи предрасполагает немецкоговорящих форумчан к негативному восприятию неупорядоченного ритмического рисунка звучания русской речи. 
4) Использование различного рисунка движения тона в дружеской и агрессивной коммуникации побуждает немцев квалифицировать речь русскоговорящих в очевидных ситуациях дружеского общения как конфронтационную коммуникацию.

5) Несмотря на превалирующую общую негативную оценку восприятия русского произношения немецкими форумчанами, встречается достаточное количество примеров, свидетельствующих о позитивном восприятии определённых аспектов звучания русской речи. Очевидно, внеязыковые факторы способствуют тому, что немецкие форумчане дают одним и тем же фонетическим особенностям произношения в русском языке противоположные оценки. В первую очередь это касается степени укоренения у форумчан традиционных немецких стереотипов о России и русских.

6) Установление взаимосвязи стереотипной картины мира в сознании носителей немецкого языка и их оценкой эстетической стороны звучания русской речи может стать предметом дальнейших исследований.

(C) Шестерина E.A., 2021

\section{Список литературы}

1. Величкова Л. В. Психолингвистическая основа исследования эмоциональности звучащей речи / Л.В. Величкова // Вопросы психолингвистики. 2007. №5. С. 20-27.

2. Глушак В. М. Роль эмоций в структуре речеповеденческих модусов / В.М. Глушак // Вестник Воронежского государственного университета. Серия: Лингвистика и межкультурная коммуникация. 2006. № 2. С. 50-57.

3. Каск Н. А. Фонетический портрет солдата вермахта в коммуникативном сознании российского зрителя / Н.А. Каск // Collegium linguisticum: материалы ежегодной конференции Студенческого научного общества МГЛУ, Москва, 14-15 марта 2019 года. 2019. М.: Московский государственный лингвистический университет, 2019. С. 253-261.

4. Николаева Т. М. Интонация сложного предложения в славянских языках / Т.М. Николаева. М.: Наука, 1969. 286 с.

5. Поспелова С. Н. Аудитивный анализ спонтанной звучащей детской речи с использованием каталога просодических признаков / С.Н. Поспелова // Вестник Воронежского государственного университета. Серия: Лингвистика и межкультурная коммуникация. 2018. № 4. С. 88-93.

6. Потапова Р. К. Язык, речь, личность / Р.К. Потапова, В.В. Потапов. М: Языки славянской культуры, 2006. 496 с.

7. Рогова М. К. Сопоставление фонетических систем немецкого и русского языков / М.К. Рогова // Русский язык за рубежом. 1979. №1(57). С. 18-23.

8. Bose I. Doch da sin ja' nur muster: Kindlicher Sprechausdruck im sozialen Rollenspiel / I. Bose. Frankfurt am Main: Peter Lang, 2003. 438 S.

9. Aktuelle Spracheinstellungen in Deutschland: erste Ergebnisse einer bundesweiten Repräsentativumfrage / L.M. Eichinger, A.-K. Gärtig, A. Plewnia u.a. Mannheim: Institut für Deutsche Sprache, 2009. 63 S.

10. Stock E. Wirkungen des Stimm- und Sprechausdrucks / E. Stock // Sprechwirkung: Grundfragen, Methoden und Ergebnisse ihrer Erforschung. Berlin: Akademie Verlag, 1991. S. 59-142.

11. Trojan F. Biophonetik / F. Trojan. Zürich: Bibliographisches Institut AG, 1975. 264 S.

\section{References}

1. Velichkova, L. V. Psikholingvisticheskaia osnova issledovaniia emotsional'nosti zvuchashchei rechi [Psycholinguistic basis for the study of emotionality of sounding speech] / L.V. Velichkova // Voprosy psikholingvistiki. 2007. №5. S. 20-27.

2. Glushak, V. M. Rol' emotsii v strukture rechepovedencheskikh modusov / V.M. Glushak [The role of emotion in the structure of speech behavior modus] // Vestnik Voronezhskogo gosudarstvennogo universiteta. Seriia: Lingvistika i mezhkul'turnaia kommunikatsiia. 2006. № 2. S. 50-57.

3. Nikolaeva, T. M. Intonatsiia slozhnogo predlozheniia $v$ slavianskikh iazykakh [Intonation of a complex sentence in Slavic languages] / T.M. Nikolaeva. M.: Nauka, 1969. $286 \mathrm{s.}$

4. Pospelova, S. N. Auditivny analiz spontannoy zvuchashchei detskoi rechi s ispol'zovaniem kataloga prosodicheskikh priznakov [Auditive analysis of a spontaneous children's speech by means of a catalogue of prosodic features] / S.N. Pospelova // Vestnik Voronezhskogo gosudarstvennogo universiteta. Seriia: Lingvistika i mezhkul'turnaia kommunikatsiia. 2018. № 4. S. 88-93.

5. Potapova, R. K., Potapov, V. V. Iazyk, rech', lichnost' [Language, speech, personality] / R.K. Potapova, V.V. Potapov. M: Iazyki slavyanskoy kul'tury, 2006. $496 \mathrm{~s}$.

6. Rogova M. K. Sopostavlenie foneticheskikh sistem nemetskogo i russkogo iazykov [Comparasion of phonetic systems of German and Russian]/ M.K. Rogova // Russkii iazyk za rubezhom. 1979. №1(57). S. 18-23. 
7. Bose, I. Doch da sin ja' nur muster: Kindlicher Sprechausdruck im sozialen Rollenspiel / I. Bose. Frankfurt am Main: Peter Lang, 2003. 438 S.

8. Aktuelle Spracheinstellungen in Deutschland: erste Ergebnisse einer bundesweiten Repräsentativumfrage / L.M. Eichinger, A.-K. Gärtig, A. Plewnia u.a. Mannheim: Institut für Deutsche Sprache, 2009. 63 S.

9. Stock, E. Wirkungen des Stimm- und Sprechausdrucks / E. Stock // Sprechwirkung: Grundfragen, Methoden und Ergebnisse ihrer Erforschung. Berlin: Akademie Verlag, 1991. S. 59-142.

10. Trojan, F. Biophonetik / F. Trojan. Zürich: Bibliographisches Institut AG, 1975. 264 S.

\section{Сведения об авторе:}

Шестерина Елена Александровна - кандидат филологических наук, доцент кафедры немецкого языка МГИМО (Россия, Москва). Сфера научных и профессиональных интересов: психолингвистика, культура речи, фонетика немецкого языка, методика преподавания немецкого языка. E-mail: niky.07@mail.ru

\section{About the author:}

Elena A. Shesterina - PhD, Assistant Professor of Department of the German Language, MGIMO University (Moscow, Russia). Spheres of research and professional interest: psycholinguistics, culture of speech, German phonetics, German teaching methodology. E-mail: niky.07@mail.ru 